This is the author's final version of the work, as accepted for publication following peer review but without the publisher's layout or pagination. The definitive version is available at http://dx.doi.org/10.1142/S1464333219500091

\title{
Explanations for the quality of biodiversity inputs to Environmental Impact Assessments (EIA) in areas with high biodiversity value
}

Felicity Swanepoel - green-scene environmental, South Africa, Email felicity@greenscene.co.za

Francois Retief - North-West University, South Africa, Email francois.retief@nwu.ac.za* Alan Bond - University of East Anglia, United Kingdom; North-West University, South Africa, Email alan.bond@uea.ac.uk

Jenny Pope - Integral Sustainability, Australia; School of Science, Edith Cowan University, Western Australia; Research Unit for Environmental Sciences and Management, North-West University, South Africa, Email jenny@integral-sustainability.net

Angus Morrison-Saunders - School of Science, Edith Cowan University, Western Australia; Research Unit for Environmental Sciences and Management, North-West University, South Africa, Email a.morrison-saunders@ecu.edu.au

Morgan Hauptfleisch - Department of Agriculture and Natural Resources Sciences, Namibia University of Science and Technology, Namibia, Email mhauptfleisch@nust.na Monica Fundingsland - Sustainability Department, Equinor ASA, Norway, Email mofun@equinor.com

*corresponding author 


\title{
Explanations for the quality of biodiversity inputs to Environmental Impact Assessments (EIA) in areas with high biodiversity value
}

\begin{abstract}
:
Biodiversity is under significant threat globally and therefore the biodiversity input to environmental impact assessment (EIA) is important. The quality of biodiversity inputs need to be high if biodiversity is to be protected, especially in areas with high biodiversity value. Here we follow-up quality reviews of biodiversity inputs to EIA reports, through interviews with the biodiversity specialists who authored the biodiversity inputs, in order to find explanations for the quality results. This is the first quality review research to systematically engage with biodiversity specialists in this way. The biodiversity specialists highlighted professional registration as a key factor supporting strengths around professional conduct and gathering of baseline information. Weaknesses identified relate to review areas dealing with alternatives, public participation, prediction, as well as management actions and monitoring arrangements, which seem to be the result of a lack of understanding and/or agreement on the role of the biodiversity specialists in the EIA process. The research results suggest that ideally biodiversity inputs should not be seen as a one-off contribution but rather as an iterative contribution during different stages of the EIA process.
\end{abstract}

Key words: quality, biodiversity impact assessment, decision making, environmental impact assessment, review, follow-up, South Africa

\section{Introduction and problem statement}

World-wide biodiversity is under significant threat from human activities and it is claimed that the planet is amidst a sixth global extinction event (Leadley, et al., 2010; Steffen et al., 2015). Environmental impact assessment (EIA) has been introduced globally as a policy instrument to inform better decision making (Morgan, 2012), and generally includes specific reference to ecological and/or biodiversity impacts. The Institute for Environmental Management and Assessment (IEMA, 2011), for example, found that ecological impacts were included within the scope of United Kingdom (UK) EIAs more than any other impact category. Indeed many EIA systems specifically and narrowly define the mandate and purpose of EIA as to protect the biophysical environment and promote the conservation of biodiversity. The consideration of biodiversity impacts becomes especially important in areas with high biodiversity value such as biodiversity hotspots (Barrow, 2006; Glasson, et al., 2012; Morgan, 2012; Pope, et al., 2013; Retief, et al., 2016).

Various guidelines exist on international best practice in assessing biodiversity impacts (CBD, 2002; Gontier, et al., 2006; Rajvanshi, et al., 2009), and some countries have also developed country specific guidelines (Brownlie et al., 2006a; CBD, 2006). Although there seems to be general international agreement on the need for, and the objectives associated with considering biodiversity in EIA, the way in which biodiversity considerations are included in 
EIA differs. For example, biodiversity impacts might be described in a separate chapter within an EIA (Atkinson, et al., 2000; Geneletti, 2002; Treweek, 1999) or, as in South Africa, through a specialist study that supplements and informs the overall EIA on the significance of potential biodiversity impacts. These differences also lead to different terminology depending on the jurisdiction, for example, reference to Ecological Impact Assessment in the UK (see Treweek, 1999) and Biodiversity Impact Assessment (BIA) in South Africa (Brownlie, 2005). Notwithstanding these contextual differences and nuances, the need to ensure good quality biodiversity inputs to EIA, is universal.

Previous research has highlighted several weaknesses in the way biodiversity has been considered in EIA such as conducting baseline studies over insufficient time periods and across inappropriate seasons (Treweek, 1996; Thompson et al., 1997; Byron et al., 2000) and a general tendency to focus on species and habitats rather than ecological processes (Byron et al., 2000; Rouget et al., 2003; Brownlie et al., 2006). There are also numerous challenges to be overcome to ensure the quality of any consideration of biodiversity impacts, including difficulties in incorporating biodiversity impact significance thresholds (Cooper and Sheate, 2002; De Villiers et al., 2008; Slootweg, 2005; Warnken and Buckley, 1998) and designing detailed mitigation measures and biodiversity monitoring plans (Byron et al., 2000; Söderman, 2006; 2006; Treweek et al., 1993; Treweek, 1996; Mandelik et al., 2005; Söderman, 2005). At the time of writing the most recent research published on the quality of biodiversity inputs to EIA is by Hallat et al. (2015), specifically focussing on EIA practice within the Cape Floristic Region (CFR) biodiversity hotspot in South Africa. The research confirmed many of the general weaknesses and challenges already identified in the literature but also highlighted a number of positive outcomes such as the incorporation of ecosystems processes in baseline studies and assessments, as well as the wide adoption of a precautionary approach to impact prediction.

Previous studies into the biodiversity inputs to EIA have largely been conducted through evaluation of the quality of BIA reports using report quality review packages (e.g., Söderman, 2005; Briggs and Hudson, 2013; Drayson et al., 2015; Hallat et al., 2015). Whilst this approach has enabled the development of a robust understanding of the quality of biodiversity inputs, it does not explain why the level of quality is achieved. The aim of this research is therefore twofold: firstly to evaluate the quality of biodiversity inputs to EIA in areas with high biodiversity value and secondly to explore the underlying reasons for the quality results. As far as we could establish, this has not been done empirically before.

Our research was conducted in South Africa, which presents a particularly good context for exploring biodiversity inputs to EIA because of its high levels of biodiversity (UNESCO, 2004), as well as having a well-established and mature EIA system (Kidd et al., 2018). Moreover, the consideration of biodiversity is an explicit legal requirement within the context of EIA whose legal mandate and purpose is aligned with the so-called 'environmental right' contained in Section 24 of the Constitution of the Republic of South Africa (Act 64 of 1996) as well as the guiding principles contained in Section 2 of the National Environmental Management Act (NEMA - Act 107 of 1998). National guidelines for the consideration of biodiversity impacts in EIA have been aligned with international best practice (Brownlie et al., 2006a; CBD, 2006). Therefore learning from South Africa could well be applicable more broadly or, at the very least, suggest some new avenues for research associated with the quality of biodiversity inputs to EIA in areas of high biodiversity value, and where there is an alignment with international best practice in the consideration of biodiversity in EIA. In practice, EIA in South 
Africa is characterised by specific specialist studies dealing with different biophysical, social and economic aspects, which might include social impact assessments (SIA), heritage impact assessments (HIA), visual impact assessments (VIA), etc - and BIA. The consultant responsible for managing the overall EIA process is called an environmental assessment practitioner (EAP) and, if the EAP responsible for the EIA scopes biodiversity in, then a specialist study referred to as a BIA will be included in the final EIA report to assess the relative significance of biodiversity impacts and recommend possible mitigation measures. The EIA process within the South African context is done according to strictly prescribed legal timeframes, which has particular implications for specialist studies, as will become clear in this paper. It is also important to note that ecosystem services assessment is not included in the scope of this paper, albeit an important theme in the literature dealing with biodiversity in EIA (Peh et al., 2013).

In the following section we explain the research methods adopted, both for quality review and for investigating the underlying causes of the quality outcome. We then present the data analysis and results in Section 3, and conclude in Section 4.

\section{Methods}

Our research was undertaken in four main steps: i) identification of an appropriate study area which represents an area of high biodiversity value, ii) identifying and sourcing ElA reports within the study area for which BIAs were conducted, iii) application of a quality review package to the selected sample of BIAs, to determine their quality, iv) conducting a survey and follow-up interviews with relevant consultants to verify, and explore the reasons for, the quality results achieved from step iii. The following sections expand on each of these.

\subsection{Identification of the study area}

An evaluation of the quality of BIAs is most valuable in areas recognized as having high biodiversity value, such as so-called biodiversity hotspots. A biodiversity hotspot is defined as a biogeographic region which is a noteworthy reservoir of biodiversity as well as an area which is threatened with destruction (UNESCO, 2004). Globally there are 34 identified biodiversity hotspots. South Africa is an ideal focus for the research due to its high levels of biodiversity, and the location of three biodiversity hotspots within its borders, namely: CFR; MaputalandPondoland-Albany (MPA); and Succulent Karoo (SK) hotspots. The CFR has already been researched by Hallat et al., (2015) and therefore a focus on one of the other two hotspots avoids some duplication.

For this research the MPA was selected on pragmatic grounds, given the availability of a sufficient sample. The MPA hotspot lies between the Indian Ocean and the Great Escarpment and spans three southern African countries namely Mozambique, South Africa and Swaziland - see Figure 1. This research focuses only on the South African section. The hotspot area incorporates six of South Africa's eight biomes over nearly $275,000 \mathrm{~km}^{2}$. The MPA is the second-richest floristic region in Southern Africa (after the CFR) and the second-richest floristic region in Africa for its size. There are an estimated 8100 plant species which occur in this biodiversity hotspot, of which approximately 1900 are endemic to the area. 
Figure 1: Location of the MPA

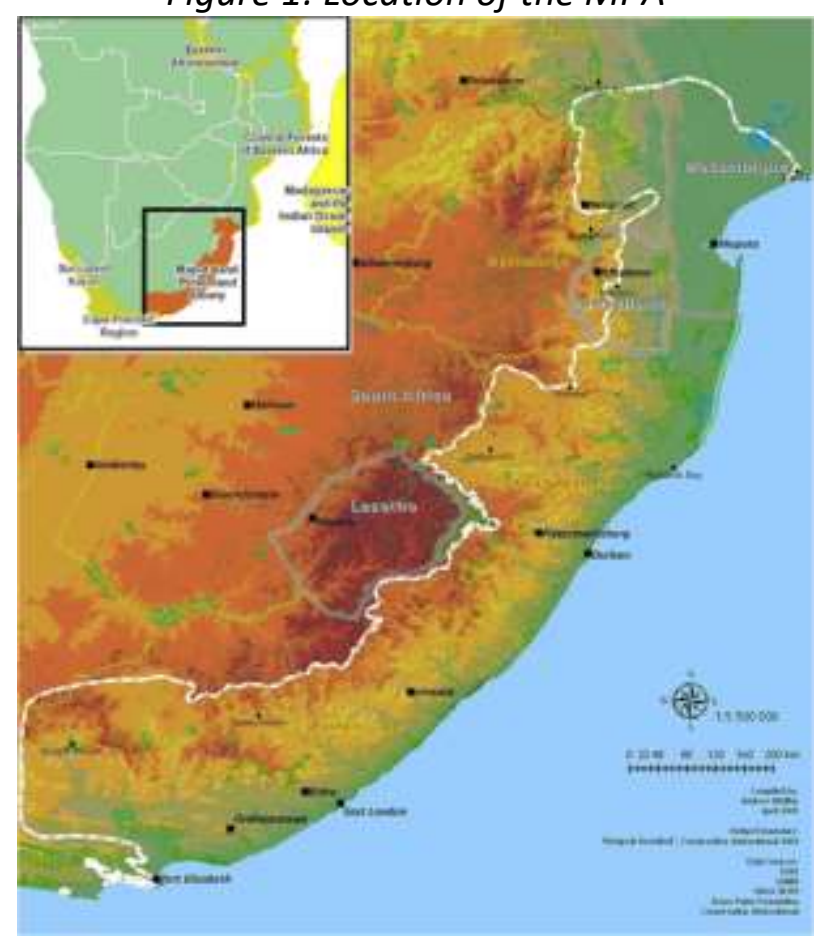

\subsection{EIA report selection}

There is no database on the total number of EIAs conducted within the MPA which means that a representative sample cannot be identified. Hence the research had to rely on so-called 'replication logic' (Yin, 2003) where the addition of more cases is unlikely to change the general patterns that emerge from the data. Based on other quality review studies identified in the literature, a sample of between 20 and 30 reports is usually sufficient to reach a sufficient level of saturation (see for example Sandham et al., 2013; Hallat et al., 2015). The sourcing of reports relied on internet searches; and direct communication with the KwazuluNatal provincial environmental authority in South Africa, in which the largest portion of the MPA hotspot is located, and with consultancy firms responsible for undertaking the BIAs. A total of 26 EIAs, incorporating specialist BIAs, were identified in this way. These BIAs were sourced from six different consultancies (with no more than five reports from a single consultancy) and were conducted for a range of activities/development types (agricultural, commercial, infrastructure, light industry and residential) as well as nine types of biodiversity assessment - as summarised in Table 1.

Table 1: Summary of BIA report sample

\begin{tabular}{|l|c|c|c|c|c|c|c|c|c|c|}
\hline \multicolumn{2}{|c|}{$\begin{array}{c}\text { Types and Numbers of } \\
\text { Activities/ assessments }\end{array}$} & \multicolumn{9}{c|}{ Types of biodiversity assessments covered within the BIAs } \\
\hline $\begin{array}{l}\text { Activity/ } \\
\text { Development } \\
\text { Type }\end{array}$ & $\begin{array}{c}\text { Number } \\
\text { of BIA } \\
\text { Reports }\end{array}$ & Avifaunal & $\begin{array}{c}\text { Mamm } \\
\text { als }\end{array}$ & Frogs & Bats & Reptiles & $\begin{array}{c}\text { Freshwater/ } \\
\text { Estuarine }\end{array}$ & Botanical & Ecological & Wetlands \\
\hline Agricultural & 2 & 1 & 1 & 1 & & 1 & - & 1 & 2 & 1 \\
\hline Commercial & 6 & 3 & 3 & 2 & 1 & 3 & 3 & 3 & 4 & 4 \\
\hline Infrastructure & 8 & 2 & 4 & 1 & 1 & 1 & 2 & 4 & 7 & 6 \\
\hline Light Industry & 2 & - & - & - & - & - & - & - & 2 & 1 \\
\hline Residential & 8 & 3 & 4 & 3 & 1 & 3 & 2 & 5 & 6 & 6 \\
\hline Total & 26 & 9 & 12 & 7 & 3 & 8 & 7 & 13 & 21 & 18 \\
\hline
\end{tabular}




\subsection{Application of BIA quality review package}

Review packages are widely used to review the quality of EIA documentation such as scoping reports, environmental statements, specialist studies, etc. across different sectors and in different contexts (Barker and Jones, 2013; Canelas, et al., 2005; Cashmore, et al., 2002; Lee, et al., 1999; McGrath and Bond, 1997; Sandham, et al., 2008a,b, 2010a, 2013a). Hallat et al. (2015) previously designed and applied a review package for evaluating the quality of biodiversity inputs to EIA, the content of which reflects international best practice (CBD, 2002; Goutier, et al., 2006; Rajvanshi, et al., 2009) as well as South African legal compliance requirements and guidelines (Brownlie et al., 2006a; CBD, 2006). We considered the application of the Hallat et al. (2015) review package as desirable for this research because it is recent, already tailored to the South African context and has been published in the peer reviewed literature. The use of the package also allows for comparison of quality results over time.

The structure and methodology underpinning the Hallat et al. (2015) review is based on the well accepted and widely applied Lee et al. ElA Review Package (Lee, et al., 1999) presented in Table 2. Readers are directed to Hallat et al. (2015) for details of the derivation of this method. The review relies on a bottom up process across three tiers of evaluation, starting with review criteria (51), then review areas (11) and ultimately an overall review score is determined. This is therefore a deductive approach relying on predetermined review criteria and related review areas. Such an approach is helpful in providing a structured and systematic way to analyse and describe the review results.

Table 2: Summary of BIA review areas and criteria

\begin{tabular}{|l|c|}
\hline Review area 1: Expertise and professional conduct & Review area 7: Inclusion of legal aspects \\
1.1 Qualifications, expertise and experience & 7.1 Description of legal context \\
1.2 Details of specialist & 7.2 Policy and planning context of project \\
1.3 Declaration of independence & 7.3 Inclusion of standards and guidelines \\
1.4 Validity of information & 7.4 Support of policy, plans and programmes \\
Review area 2: Adequacy and sufficiency of information & 7.5 Likely non-compliance with legislation \\
2.1 Information for decision making purposes & Review area 8: Public Participation \\
2.2 Terms of Reference & 8.1 Description of participation processes \\
2.3 Traditional or indigenous information & 8.2 Key I\&AP input to the EIA process \\
2.4 Uncertainties and gaps in information & 8.3 Provision for public involvement \\
2.5 Degree of confidence & Review area 9: Prediction and assessment of \\
Review area 3: Clarity and inclusiveness of report & impacts \\
3.1 Non-technical summary & 9.1 Environmental operation scenarios \\
3.2 Time and space boundaries & 9.2 Assessment approach and methodology \\
3.3 Sources of information & 9.3 Linkages to other specialist studies \\
3.4 Description of specialised methodologies & 9.4 Criteria used to assess impacts \\
3.5 Purpose and scope of study & 9.5 Impacts on ecological processes \\
3.6 Justification of opinions or statements & 9.6 Indirect or cumulative impacts \\
3.7 Adequacy of conclusions & 9.7 Linkages from identification to evaluation \\
3.8 Summary impact assessment table & 9.8 Explicitness of consequences \\
3.9 Potential implications of findings & 9.9 Irreversibility and irreplaceability of impacts \\
Review area 4: Description of project & 9.10 Assessment i.t.o. desired state \\
4.1 Purpose and need for project & 9.11 Identification of beneficiaries \\
4.2 Description of project and alternatives & Review area 10: Recommended management \\
Review area 5: Baseline description of affected & actions \\
environment & 10.1 Summary of key management actions \\
5.1 Characteristics of affected environment & 10.2 Mitigation of positive and negative impacts \\
\hline
\end{tabular}


5.2 Description of surrounding environment

5.3 Maps, plans and photographs

Review area 6: Consideration of alternatives

6.1 Inclusion of reasonable alternatives

6.2 Comparison of alternatives

6.3 Identification of best environmental option
10.3 Precautionary principle

10.4 Viability and practicability of mitigation

11: Monitoring

11.1 Monitoring programmes

11.2 Viability and practicability monitoring

A qualitative rating scale was used similar to that proposed in the Lee et al. package (1999), see Table 3. Ultimately an overall grade was awarded based on the outcome of the different review area scores. Review areas and criteria are not weighted, rather, the overall grade relies on a subjective overall judgement based on all the review area scores, which themselves are based on judgement associated with review criteria scores. A variation to the original Lee et al. approach was that the ratings were performed by a single researcher, not multiple teams that were then agreed by consensus. An alternative form of verification was employed as explained in the next section.

Table 3: Review rating symbols and descriptions

\begin{tabular}{|c|l|}
\hline Symbol & \multicolumn{1}{|c|}{ Description } \\
\hline A & Assessment was complete and well performed \\
\hline B & Satisfactory with minor omissions/ inadequacies \\
\hline C & Just satisfactory, with emissions and inadequacies \\
\hline D & Just unsatisfactory due to omissions/ inadequacies although parts may be satisfactory \\
\hline E & Not satisfactory - significant omissions/ inadequacies \\
\hline F & Very unsatisfactory - poorly done or simply not attempted \\
\hline
\end{tabular}

\subsection{Survey and follow-up interviews}

A survey questionnaire was sent out via e-mail to each of the six consultancies that conducted the BIAs. All the consultancies included in the survey were well established, and their specialists had many years of experience in the relevant fields combined with professional registrations such as with the South African Council for Natural Scientific Professionals (SACNASP). The outcomes of the quality review were presented to the respondents for the reports they authored. They were then asked to comment in writing under each of the review areas on:

1) whether they concurred with the review results; and

2) what they would consider to be possible reasons and/or explanations for the results.

In certain instances, follow-up personal interviews were also undertaken with the specialists (all of whom responded to the questionnaire) to confirm and clarify their written comments. These specialists requested anonymity which has been respected in this paper. This process of verifying the quality review rating with the BIA experts responsible, and also exploring the underlying reasons for the results, is an innovative aspect of this research. Because the sample of consultants cannot claim to be representative, reference in the analysis to quantitative percentage or proportion of the sample seems questionable. Therefore, the interview feedback does not lend itself to quantitative percentage/proportional analysis, but rather relied on rich descriptions of views and opinions. 


\section{Results and discussion}

As explained in the previous section the data analysis relied on a deductive approach, by evaluating against pre-designed review areas and related review criteria based on international and context specific best practice (CBD, 2002; Brownlie et al., 2006a; CBD, 2006). To align the discussion with the deductive approach, this section is structured around the sub-headings of the 11 review areas, while the discussion under each review area drills down to the individual review criterion level to provide in-depth argumentation. By structuring this section around the review areas we maintain a systematic and structured approach to the discussion. As point of departure for the discussion Table 4 provides a summary of the total number of and percentage of review scores per review area.

Table 4: Summary of results

\begin{tabular}{|c|c|c|c|c|c|c|c|c|c|c|c|c|c|}
\hline \multirow{3}{*}{\multicolumn{2}{|c|}{ Review Areas }} & \multicolumn{12}{|c|}{ Percentage of symbol scores } \\
\hline & & \multicolumn{2}{|c|}{ A } & \multicolumn{2}{|c|}{ B } & \multicolumn{2}{|c|}{ C } & \multicolumn{2}{|c|}{ D } & \multicolumn{2}{|c|}{$\mathbf{E}$} & \multicolumn{2}{|c|}{$\mathbf{F}$} \\
\hline & & $\%$ & $\mathrm{Nr}$ & $\%$ & $\mathrm{Nr}$ & $\%$ & $\mathrm{Nr}$ & $\%$ & $\mathrm{Nr}$ & $\%$ & $\mathrm{Nr}$ & $\%$ & $\mathrm{Nr}$ \\
\hline 1 & Expertise and professional conduct & 8 & 2 & 69 & 18 & 23 & 6 & 0 & - & 0 & - & 0 & - \\
\hline 2 & Adequacy and sufficiency of information & 8 & 2 & 19 & 5 & 27 & 7 & 38 & 10 & 8 & 2 & 0 & - \\
\hline 3 & Clarity and inclusiveness of report & 0 & - & 12 & 3 & 61 & 16 & 23 & 6 & 4 & 1 & 0 & - \\
\hline 4 & Description of project & 0 & - & 31 & 8 & 46 & 12 & 8 & 2 & 15 & 4 & 0 & - \\
\hline 5 & Description of baseline environment & 62 & 16 & 23 & 6 & 15 & 4 & 0 & - & 0 & - & 0 & - \\
\hline 6 & Consideration of alternatives & 0 & - & 0 & - & 8 & 2 & 23 & 6 & 15 & 4 & 54 & 14 \\
\hline 7 & Inclusion of legal aspects & 8 & 2 & 23 & 6 & 46 & 12 & 19 & 5 & 0 & - & 4 & 1 \\
\hline 8 & Stakeholder consultation & 0 & - & 0 & - & 0 & - & 15 & 4 & 23 & 6 & 62 & 16 \\
\hline 9 & Prediction and assessment of impacts & 0 & - & 4 & 1 & 27 & 7 & 46 & 12 & 19 & 5 & 4 & 1 \\
\hline 10 & Recommended management actions & 19 & 5 & 27 & 7 & 35 & 9 & 8 & 2 & 4 & 1 & 8 & 2 \\
\hline 11 & Monitoring & 0 & - & 0 & - & 46 & 12 & 15 & 4 & 0 & - & 38 & 10 \\
\hline
\end{tabular}

Figure 2 uses the data in Table 4 to illustrate the percentage scores of the review criteria related to the different review areas. It suggests that review areas 6 (alternatives), 8 (consultation), 9 (prediction) and 11 (monitoring) performed particularly poorly with more than $50 \%$ unsatisfactory scores (D-F). Review areas of particular strength include review areas 1 (expertise) and 5 (baseline) based on the higher relative proportion of grades A or $B$ awarded. 
Figure 2: Percentage scores against different review areas

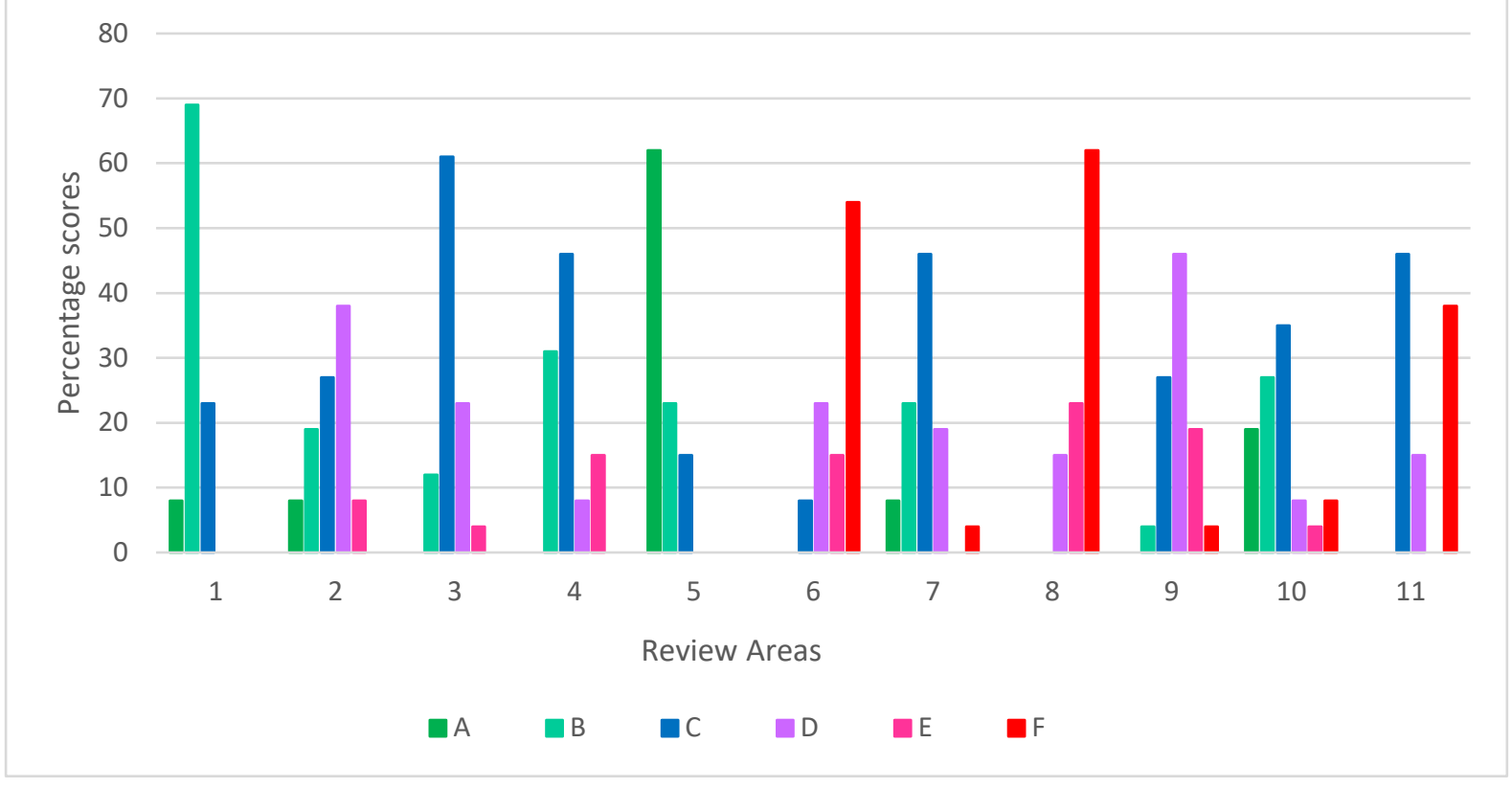

Although the raw data consisted of 51 criteria and 26 BIAs, the following discussion focusses on certain key criteria underpinning the different review areas. It explores the validation and reasons for the review scores based on the biodiversity specialist questionnaire and interview feedback as well as why these review areas are important to ensure sound biodiversity inputs to EIA.

\section{Review Area 1: Expertise and professional conduct}

This review area generally scored well (see Table 4 and Figure 2). Most reports included a comprehensive summary of the company details, qualifications of the specialists, professional affiliations as well as relevant experience of the specialists listed in the reports (criterion 1.1 and 1.2). It is difficult to know how the pool of biodiversity professionals in South Africa compares internationally, although the results suggest that the necessary expertise to conduct BIAs is readily available within the MPA hotspot. Many of the reports also contained a 'declaration of independence' by the biodiversity consultant which is a unique requirement within the South African EIA system for specialists (Münster, 2005), as well as for EAPs (criterion 1.3). This requirement aims to promote credibility and validity to BIAs and EIAs, as it requires the EAP and/or specialist to maintain and declare no vested interest in the project (criterion 1.4).

The specialists generally agreed with the positive outcome for this review area, although they did feel that they could expand the reference to their expertise even more by including more detailed CVs and lists of past experience with related projects. The specialists felt that the requirement by the relevant authorities reviewing the EIAs that BIA specialists need to be registered with SACNASP has been a strong driver for ensuring suitable expertise and professional conduct. SACNASP is the legislated regulatory body for natural science practitioners in South Africa. The natural sciences encompass a wide range of scientific fields covering all of the basic sciences and many of their applied derivatives. Interviewees pointed out that SACNASP has a strict code of conduct which needs to be adhered to by all members to retain their registration, and this assists in the quality of the reports. However, although the specialists agreed with the high level of available expertise and professional conduct, they 
did warn that, as one interviewee puts it, "as the industry becomes more competitive, clients might go for the cheaper option, and thereby compromise on quality and expertize as a result." The point seems to be that the enforcement of professional registration requirements (where they exist) by the relevant authorities is an effective and relatively easy way to secure recognised expertise and ensure professional conduct.

\section{Review Area 2: Adequacy and sufficiency of information}

For this review area, although many of the reports covered a wide range of biodiversity information, the majority lacked in-depth site specific information. The lack of site specific information seems to have prompted the inclusion of disclaimers confirming and explaining, for example, that insufficient time was given for a detailed report and/or that the fieldwork was completed during the incorrect season (criterion 2.4). The limited timeframe for the BIA is often caused by the strict timeframes set out in the EIA process itself. This weakness is very much in line with international trends which express that commercial pressure, in terms of timeframes and financial constraints, contribute to insufficient time allocation for considering biodiversity impacts (Byron, et al., 2000; Retief and Chabalala, 2009; Thompson, et al., 1997; Treweek, 1996; Bond, et al., 2014).

One of the specialist reports included a section heading which stated "Constraints and Limitations of Short Duration Ecological and Faunal Surveys", in which the different constraints within the study are listed, including: limitation of baseline study, limitation of specialist surveys as part of BIA (e.g. aquatic or estuarine surveys), lack of comprehensive biodiversity information for the survey area, lack of historic data for the area as well as lack of information regarding red data species within the site area. The results did however suggest that in cases where well defined terms of reference (ToRs) were in place the reports tended to score better results (criterion 2.2), which mirrors the findings of research examining the value of well-drafted ToRs internationally (Keatimilwe and Ashton, 2005). The ToR is drafted as part of the Scoping phase when the plan of study for EIA is accepted by the relevant authority. This means that the scoping phase is a critical step from a BIA perspective.

The specialists generally agreed with the quality scores and confirmed that some of the reasons for the 'just satisfactory' and 'just unsatisfactory' scores are that they are given insufficient information regarding the project to begin with and they often had very little existing baseline information, restricted budgets and short timeframes to work with (criterion 2.1). As one specialist stated, "time constraints imposed by the client and the EAP often limit the amount of time spent on reporting and sampling". This lack of information in some cases leads to instances where, "reports are padded by probability and functionality indexes, species accounts, and tables with limited actual species lists for specific sites". Previously in Section 1, we identified a range of international studies reporting similar problems with baseline studies and the integration of biodiversity information into EIA practice that resonate with these findings. Lack of budget also often leads to a shortfall of adequate specialist surveys pertaining in particular to mammals, avifauna, reptiles, amphibians as well as invertebrates, "The majority of databases are outdated or poorly ground-truthed resulting in inaccurate species lists as well as ecosystem, mainly wetlands, delineation" and "Specialists can become complacent after many years. This is reflected in poor quality reporting and 'lazy' sampling". These typically result in overly generalised data at inappropriate scales. In areas with high biodiversity value this may result in site specific localised rare and/or endangered species being overlooked. 
A suggested solution from the interviewees for overcoming the challenge of limited time, which leads to inadequate information, might be to have continuous long term biodiversity monitoring arrangements in areas of high biodiversity value, especially the biodiversity hotspots and to feed this information into one of the international tools, such as strategic environmental assessments (SEAs), conservation plans (C-Plans) as well as newer methods such as the online data seen on the Global Biodiversity Information Facility (GBIF) lifeboat portal which could then be accessed when BIAs require data (Retief, et al., 2007; Marais, et al., 2015). This could reduce the time needed to produce accurate site specific data, since the site specific biodiversity surveys would require mere ground truthing and/or confirmation of existing data, rather than a resource intensive data generation process from scratch.

These suggestions are consistent with long-term perspectives for more effective baseline studies. For example, Hollick (1986, p170) suggested that two types of baseline information are needed for EIA, being a combination of 'project-specific data relevant to the particular site and its immediate surroundings, and less detailed regional baseline data to provide the temporal and spatial context'. Hilborn and Walters (1981, p267) argued for implementation longterm baseline studies of 'unperturbed systems to establish natural baselines'. More recently Noble (2015) notes that the time period and spatial scale of baseline studies undertaken for EIA projects need to be designed appropriately to enable the past, present and likely future state of the environment to be understood. These international perspectives, in combination with the finding of this research, point to the need for a re-focusing for why and how baseline studies are conceived and executed in South African practice.

\section{Review Area 3: Clarity and inclusiveness of report}

One of the most important requirements to improve the clarity and inclusiveness of reports is the inclusion of a concise executive summary which adequately explains the results of the findings within the report as well as the recommendations (Keatimilwe and Ashton, 2005). The research found that in many cases the specialists were drawing conclusions for which they did not always have adequate data or available information to substantiate fully (criteria 3.3 and 3.5). The specialists agreed with this observation and suggested that expectations from EAPs and decision makers is for them to provide conclusive results and recommendations, even when they are not justified to do so, as for example the necessary data within the MPA is not available, or the surveys were conducted in the wrong season. Therefore the conclusions presented should be caveated with the limitations contained in the full assessment, but this is typically not done. The specialists felt that it is important that EAPs and decision makers understand that clarity does not mean being more conclusive but rather being clear on what we know and what we don't know, therefore also being explicit and clear about uncertainties and limitations to BIA results (criterion 3.6). The disconnect between the content of the BIA report (especially discussion on uncertainties and limitations which are typically not reflected in the summary) and its concluding summary, needs to be addressed, since the executive summary is what decision makers normally tend to focus on (criterion 3.1).

The specialists also felt that the weaknesses in this area were magnified when different specialists each worked on individual reports and the reports were not properly collated and integrated, e.g. a botanist on the vegetation report and a soil scientist on the soils. In cases where various specialists will each be working on their specific disciplines it is important that 
they are all communicating and that they jointly compile the overall BIA report. One specialist said that a "lack of collaboration between different specialists during EIAs can result in conflicting results". So the challenge for inclusiveness is not only with the way in which the $\mathrm{BIA}$ is incorporated into the overall EIA, but also the degree of collaboration between the various specialists contributing to the $\mathrm{BIA}$, in order to provide an integrated perspective on the likely significance of biodiversity impacts. This lack of integration is not only limited to biodiversity inputs, but has been recognized as a general weakness of EIA (see for example Kennedy and Ross, 1992; Morgan, 2012; Morrison-Saunders et al., 2014). Some of the reasons put forward for this apparent difficulty in integrating different specialist inputs have been a lack of common understanding of significance (Ehrlich and Ross, 2015), plurality of views on the objectives of impact assessment (Cape et al., 2018), difficulties in dealing with trade-offs (Retief et al., 2013) and incorporating different scientific traditions in EIA (Cashmore, 2004).

\section{Review Area 4: Description of the project}

The main weakness that led to the high percentage of 'just satisfactory' C scores was that most of the project descriptions in the BIA were based on general activities and generic impacts associated with a certain type of project, and this suggested the specialists had a limited understanding of the specifically planned project that was proposed for a particular site (criterion 4.2). This has also been identified as a weakness and area of concern internationally (Byron, et al., 2000; Thompson, et al., 1997; Treweek, 1996; Treweek, et al., 1993). The specialists confirmed that the need for the project and a detailed project description are often not provided to them by the EAPs (criterion 4.1). This is often because BIAs are done as a one-off exercise during the scoping and planning phases of the project, at a stage when the detailed project description is not yet clearly known or has not been finalised. One of the suggestions to overcome this is that the specialists could review their reports and make additions to them when the final more detailed project description is available, so that any important aspects that may have emerged can be properly addressed. Specialists felt that, "The majority of specialist studies are undertaken without clearly defined site boundaries, aerial photographs and details of actual construction and development activities (construction site maps)."

\section{Review Area 5: Description of the baseline environment}

Even though areas with high biodiversity value typically provide a particular challenge in terms of availability of data, this review area scored the best with $62 \%$ of the reports scoring an A and none below a 'just satisfactory' $C$ score. Description of the baseline environment is important to serve as a measurement for the level of protection that a site deserves and is also needed to assess the no-go alternative. Although the baseline environment was described adequately by the majority of cases reviewed, for some cases it was still limited to the best available data at a regional scale. This was typically due to the constraints under which the reports were done, as also highlighted under review area 2 above. The available data for the MPA varies largely with certain areas having adequate up to date data, while in other areas the data is outdated or not available. It was found that in some cases data was more than 10 years old, which place into question its accuracy. This again supports the need for long term biodiversity monitoring at a regional scale, as discussed under review area 2. Moreover, having an up to date and comprehensive set of baseline geographical data to work with, has been shown to greatly enhance the ability to gather sound biodiversity baseline data where no data exist, especially in areas with high biodiversity value (Hallat et al., 2015) 
Notwithstanding all the challenges faced by specialists as discussed under review area 2 and above, specialists found this to be the easiest of the review areas to comply with. They are of the view that as natural scientists they are comfortable with doing baseline studies (desktop and/or field surveys), even if they have to include long lists of limitations to their studies. Apart from their scientific training as highlighted in review area one, they also felt that a good score in this area could also be attributed to, "... increased availability of literature pertaining to vegetation types, geology, wetlands, and rivers as well as internet searches of virtual museums". Although there is still a long way to go to ensure general availability of comprehensive accurate and up to date biodiversity data for the MPW, there has been a meaningful increase in the availability of biodiversity data over the past two decades in South Africa in general (Marais et al., 2015; Cilliers and Retief, 2017). The general trend in the upsurge and continual refinement of baseline biodiversity data is expected to increase in South Africa, due to work being done by the South African Biodiversity Institute (SANBI) on biodiversity planning and long term monitoring (De Villiers and Hill, 2008). This could have major future benefits for the quality of BIA baseline data.

\section{Review Area 6: Consideration of alternatives}

Different project alternatives could have different potential impacts and mitigation options for biodiversity. It is therefore important that BIA considers and assess various development alternatives so that the one with the least significant biodiversity impacts and most feasible and effective management options could be considered (Brownlie, 2005). However, as already discussed under review area 4 project descriptions are normally poor and therefore it is not surprising that the consideration of alternatives was a particular area of weakness with $54 \%$ of the reports scoring an $\mathrm{F}$ and none scoring above a $\mathrm{C}$. Where alternatives were discussed there was a very low level of detail and usually only spoke of alternatives of activities which could be carried out within the buffers etc. without looking at site specific, activity alternatives (criterion 6.1). Thus the consideration of alternatives can be seen as a key weakness of BIAs within the MPA. This is in keeping with international trends which have shown that a lack of alternatives in terms of biodiversity considerations is a widespread weakness within BIA as well as EIA in general (Söderman, 2006; Treweek, 1996).

This review area was acknowledged by specialists as being a significant shortcoming of BIAs. The shortcoming was felt to be due to "the scheduling of the specialist studies once a final development plan/proposal has been identified. The specialist therefore is only presented with the preferred development proposal and is required to access that particular proposal as it will be the one that is included in the EIA for authorisation". Read together with review area 4 is seems that biodiversity specialists are involved either too early (i.e. before enough detail is available) or too late (i.e. when the project has already been decided), which suggests that BIA should not be seen as a stand-alone once off input, but rather as requiring continual engagement with the different phases of the EIA process. Recent research by De Witt et al., (2019) found similar weaknesses in relation to practice dealing with biodiversity offsets in EIA. The need for biodiversity specialists to be involved during different phases of the EIA process (and not once off) is explicitly highlighted by Brownlie (2005), who also describe different roles at different stages of the process. For example during the screening phase the biodiversity specialist would provide more of a proactive advisory role while during the impact assessment phase this role will be more investigative and analytical. This understanding does not seem to be reflected in practice. 
Another comment was "Alternatives are very rarely provided by the developers or EAPs. Alternatives usually provided are fatally flawed or not viable. The 'no-go' alternative is rarely chosen by specialists" (criteria 6.1 and 6.2). These perspectives echo similar long-standing observations of alternatives consideration in EIA internationally whereby the biases of proponents in favour of their preferred development are evident (e.g. Fairfax, 1978; Gibson 1993; Weiner, 1997; Steineman, 2001). Some specialists felt that identifying and dealing with alternatives should not be expected of the BIA, but rather covered by the EAPs. However, there was agreement that their earlier involvement in projects would allow them to make "... meaningful contributions in the determination of alternatives (site, technology or development proposal). Therefore the shortcoming is as a result of the scheduling of the specialist studies during the EIA rather than much earlier in the feasibility study for the project." One of the specialists also commented that "Alternatives are often not accepted by the client/EAP. Often this is seen as onerous or unnecessary on the client's behalf."

\section{Review Area 7: Inclusion of legal aspects}

The inclusion of the legal mandate of the BIA has been shown in international literature to be important in order to guide decision makers and authorities on how and why they need to consider the outcomes (Brownlie, 2005; Wegner, et al., 2005; Hallat, et al., 2015). South Africa has developed an extensive legal framework for biodiversity management, which provides a robust mandate for BIA (King, et al., 2009; Olivier, et al., 2009; Rumsey, 2009). The majority of reports included a broad explanation of legal aspects which are dealt with mostly at a national level, and did not consider more detailed site specific municipal by-laws etc. (criteria 7.1 and 7.2). Although legal aspects were broadly covered by most of the specialists in their reports the general view was that this subject is best covered by the EAPs during the EIA process. The specialists also felt that it was exceedingly difficult to keep up with the constantly changing legislation. They did however acknowledge the need to frame their results around existing legal mandates and recommended that more frequent workshops and/or training events on biodiversity conservation related legislation are required (criterion 7.5).

\section{Review Area 8: Public participation}

Public participation was found to be one of the weakest review areas evaluated with $62 \%$ of the reports making no mention of any form of public and/or stakeholder participation and no reports being rated higher than 'just satisfactory' $D$ score. The remainder of the reports make only a very brief mention of the social context such as people that had lived in the area previously, or of surrounding enterprises etc. (criterion 8.2). These results follow the international trends which show public participation within BIAs is severely neglected (Söderman, 2006; Thompson, et al., 1997). Some of the reports simply addressed public participation by saying: "Public Participation was not done as part of this specialist study; however it will be undertaken as part of the environmental authorisation process whereby this document will be made available to the public". There have been many studies highlighting the importance of incorporating indigenous knowledge within specialist studies and EIAs (Barrow, 2006; Sallenave, 1994; Slootweg, 2009; Stevenson, 1996), as well as the fact that the social aspect is often highly correlated with the biodiversity considerations (Dietz \& Stern, 2008; Miller \& Spoolman, 2011; Slootweg, 2005). One of the most successful ways of managing and conserving biodiversity within an area is through community buy-in, typically preceded by meaningful public participation (De Villiers, et al., 2008; Treweek, 1999). It is 
during the participation process when the relative importance of biodiversity to the local affected community can be determined. Moreover, the communication of the outcome of the BIA is also an opportunity to raise awareness and promote environmental education, especially in areas of high biodiversity value.

The specialists were of the opinion that public participation was not a requirement of the BIA and should be covered separately by the EAP during the EIA process (criterion 8.1). This is problematic since public input is typically important in identifying and evaluating the relative importance of biodiversity to local communities. Ideally the public should have an opportunity to engage with the biodiversity specialists on for example how significance around biodiversity impact were determined. However, comment was made that "Specialists rarely have the opportunity to address any possible comments on their inputs that may have arisen through public scrutiny of their reports". The specialists also raised concern over the reliability of information which is given during public participation, as it is often highly emotive and communities have been known to provide "false records pertaining to the presence of red data listed species (especially fauna) in order to stop a project from progressing". Overall it seems that there is very little public participation happening in relation to the biodiversity inputs to EIA. There seems to be ongoing confusion over both the responsibility for public participation around biodiversity impacts as well as how and when it should happen in relation to general EIA process. The inclusion of ecosystem services assessments in policy and legal requirements for BIA could broaden the scope of the assessment and provide a mechanism to advance public participation. The Toolkit for Ecosystem Service Site-based Assessment (TESSA) and other similar assessments have a strong public engagement component (Peh et al., 2013) and consider biodiversity information within the context of community value and dependence.

\section{Review Area 9: Prediction and assessment of impacts}

This review area proved to be a key weakness, with $69 \%$ of the reports receiving an unsatisfactory $D$ to $F$ score. The majority of the reports failed to include environmental thresholds which are typically used to determine the significance of biodiversity impacts (criteria 9.2, 9.4, 9.5, 9.6). This finding is seen as a widespread weakness internationally both in terms of the use of thresholds for determining significance in EIA generally (e.g. Sippe, 1997, 1999; Wood, 2008) and more specifically with regards to biodiversity thresholds being poorly included in EIA (Beanlands and Duinker, 1983; Cooper and Sheate, 2002; De Villiers, et al., 2008; Slootweg, 2005; Warnken and Buckley, 1998). The reason for this might simply be the difficulty in determining these thresholds and that we do not know what they are, especially for a complex context such as the MPA hotspot. However, one area of success has been the consideration of habitat fragmentation and ecological corridors in many of the reports, as one of the major impacts of a development. The latter consideration of fragmentation and corridors reflects the incorporation of cumulative effects thinking, which has been lacking in environmental assessment generally and BIA specifically. International literature shows that the significance of habitat fragmentation is often not considered in BIA (Mandelik, et al., 2005; Söderman, 2006; Thompson, et al., 1997; Treweek, et al., 1993). The specialists suggested that the consideration of habitat fragmentation and cumulative effects thinking was due to its incorporation in local best practice guidelines (Brownlie, 2005). Therefore, in the South African context, although cumulative effects assessment are not explicitly and/or separately done as part of BIAs, much of the thinking reflects consideration of cumulative effects. 
A major consideration which was found to negatively affect the consideration of alternatives (review area 6), was the lack of a proper description and understanding of the project itself (review area 4). This is an example where a poor result in one review area will lead to poor results in other areas. Therefore, in linking this with review area 9 it follows that without a full and comprehensive understanding of the project, accurate impact assessment and prediction is not possible (criterion 9.4). To improve performance, specialists suggest that once the project description has been finalised (along with all the other related processes and infrastructure) it should be re-submitted to the biodiversity specialist to reassess and update the BIA, if needed. These findings resonate with discussion of the role of EIA as a design tool, especially criticism around a tendency for EIAs to focus on a limited range of projects and activities (e.g. as noted previously with regards to alternatives consideration) and a 'passive model' of EIA that keeps it separate from 'direct involvement in the environmental design and management of projects' (McDonald and Brown, 1995, p484). This is notwithstanding the notion that key EIA tasks such as prediction, assessment and mitigation are intended to be iterative processes with different degrees of application occurring during screening, scoping and preparation of the proponent's EIA document (Morrison-Saunders, 2018); in short an expectation for re-assessment to occur during EIA. Specialists in our research suggested that re-assessment requirement should be included in the ToRs of the BIA.

Overall, and not surprisingly, the specialists felt that this area was covered better than the review results would suggest. However, they did acknowledge the identified weaknesses and assigned some of them to the fact that the project description was not clear. Specialists also noted that, "The impacts of certain new developments are poorly understood, for example the impact of solar farms on certain fauna and invertebrate species" and "The prediction and assessment of impacts are based primarily on specialists' personal view point". Another specialist commented "Impact prediction and assessment is often an afterthought and not given the attention it deserves. Also different methods are used which often don't follow best international practice". The overall outcome of this review area suggest that in many cases BIAs would not qualify as assessments, but rather mere status quo descriptions on the occurrence of biodiversity in certain locations.

\section{Review Area 10: Recommended management actions}

Future management actions are covered sufficiently by the majority of the reports (criterion 10.1). Many of the reports mentioned management plans and programmes to be put in place, for example, alien invasive management plans, burning programmes, etc.. Moreover, the reports often included avoidance and/or precautionary approach as a mitigation option (criterion 10.2). In terms of the application of the mitigation hierarchy, we did not find evidence in the documentation of a systematic application of the mitigation hierarchy, from avoidance to offsets. Therefore, mitigation options are described in relation to certain impacts, with limited justification against the mitigation hierarchy. We note that this paper did not further explore compensation and/or biodiversity offsets as a specific biodiversity mitigation option. For a recent study on the experience with the application of biodiversity offsets in South Africa we refer readers to De Witt et al., (2019).

The results suggest that in areas, such as the MPA hotspot, where important baseline information is sometimes not readily available, the precautionary approach is preferred, as high levels of uncertainty are almost guaranteed (Cooney, 2004; Dickson and Cooney, 2005). 
Although the reports scored relatively well for this review area, the specialists were of the view that, as for public participation, management actions should not really be part of BIAs. This view is surprising since informing the environmental management programmes (EMPr) provides an ideal opportunity to inform decision making and ultimately influence behaviour around biodiversity impacts. This is a somewhat alarming finding in view of the long-term emphasis of EIA as being a tool for establishing effective and ongoing environmental protection and management measures (e.g. Morrison-Saunders, 1996) through utilising an adaptive management approach (e.g. Holling, 1978) which is a principle for international best practice EIA (IAIA \& IEA, 1999). The specialists also acknowledged that many of the mitigation and management measures were generalised and generic, not tailored to individual projects and sites. The specialists raised the concern that they did not feel that their mitigation measures and management plans were adequately incorporated into the EIA and related EMPr and/or even the actual authorisation, and therefore the recommendations that they do give are mostly ignored by the contractors and/or developers after the development has been authorised. Such statements has however not been verified through follow-up research, although general EIA compliance monitoring and enforcement within the South African context have been found wanting (Wessels et al., 2015).

\section{Review Area 11: Monitoring}

Few of the reports discussed biodiversity monitoring in any detail and where it was mentioned it was only at a very superficial level (criteria 11.1 and 11.2). The review results show that $46 \%$ of the reports received a C score and therefore covered monitoring to a 'just satisfactory' level, while $15 \%$ were just unsatisfactory and were awarded a D score. A significant $38 \%$ of the reports did not mention biodiversity monitoring at all. Previous studies have emphasised the importance of incorporating biodiversity monitoring measures within BIAs and EIAs (Beanlands and Duinker, 1983; Treweek, 1999). This area, however, seems to continue to be a particular weakness of BIAs practice internationally and in South Africa (Byron, et al., 2000; Söderman, 2006; Treweek, 1996; Treweek, et al., 1993; Warnken and Buckley, 1998; Hallat et al., 2015).

A number of specialists felt that monitoring was covered by EAPs in the EIA process and that it was not necessary to deal with it in detail in the BIA. The latter is concerning since typically the success or effectiveness of many of the mitigation recommendation can only be determined through monitoring over time. If these biodiversity monitoring arrangements are not recommended in the BIA it will not be reflected in the overall EIA. Moreover, the specialists also mentioned that they "are rarely employed to undertake monitoring during construction and almost never during post-construction, operational and decommissioning phases". The lack of monitoring recommendations in the BIA suggest that many of the uncertainties raised in the report around biodiversity impacts cannot be addressed through adaptive management interventions during the operational phase.

\section{Conclusions and recommendations}

This research aimed to critically evaluate the quality of biodiversity inputs to EIA in areas with high biodiversity value and then to find explanations for the quality results from the biodiversity specialists. South Africa was identified as an ideal context for this research because it has a well-established EIA system combined with high levels of biodiversity. The 
research approach combined BIA report quality reviews conducted according to an existing purposefully designed report review package (Hallat et al., 2015) with follow-up interviews with the biodiversity specialists who prepared the BIA reports.

The best performing areas were around the availability of expertise and professional conduct as well as dealing with biodiversity baseline information. The local South African requirement that only formally registered natural scientists (with SACNASP) are allowed to conduct biodiversity assessments, greatly supports professional conduct and provides some level of quality assurance. Moreover, it is then not surprising that the quality of especially baseline information was found to be one of the better performing review areas, notwithstanding the challenges around limited timeframes and lack of resources. The availability of increasingly enriched biodiversity databases, albeit at a more strategic level, further supported the quality of baseline descriptions. To further strengthen BIA more fine scaled and long term monitoring arrangements are called for.

Weaknesses identified relating to for example review areas dealing with incorporating public participation and legal requirements as well as management actions and monitoring arrangements, seem to be the result of a lack of understanding and/or agreement on the role of the biodiversity specialists in the EIA process. These weaknesses were all acknowledged by the biodiversity specialists but they were not, according to them, considered as part of their responsibility, notwithstanding being included in international and local BIA best practice guidelines. Therefore, there seems to be a mismatch between the best practice biodiversity assessment guidelines and the way biodiversity considerations are incorporated in EIA practice. These views also highlight the lack of alignment and coordination between the BIA and the general EIA process. For example, the biodiversity specialist considers public participation as the EAPs responsibility, and does not see or respond to later public comments on biodiversity issues and impacts raised in the BIA report. There seems to be a need for more involvement of biodiversity specialists between the initial submission of the BIA report to the EAP, and the final incorporation of biodiversity inputs in the EIA report, especially for projects in biodiversity sensitive areas. Our findings point to perceived differences and a sense of separate and isolated roles of EAP and BIA specialists whereas ideally they should more closely share common objectives within EIA around seeking effective project design and management that will protect biodiversity.

The apparent lack of understanding and/or agreement on the role of the biodiversity specialists in the EIA process, which is reflected in a number of review areas, also points strongly to poor terms of reference for the specialist input, and poor oversight of the BIA by the EAP. The EAP appoints biodiversity specialists and should ensure that the BIA meets both legal requirements and responds to the particular challenges of each case. It appears that in many cases this oversight role is not being undertaken. A number of specialists' comments seem to reflect ignorance of, legal requirements of specialist reports in the South African EIA system and of 'good practice' BIA in general. Examples include statements that specialists felt that management actions should not be part of BIAs; that monitoring was covered by EAPs and that it was not necessary to deal with monitoring in detail in the BIA; that identifying and dealing with alternatives should not be expected of the BIA; impact prediction and assessment is often an afterthought and not given the attention it deserves; and in many cases BIAs would not qualify as assessments, but rather mere status quo descriptions on the occurrence of biodiversity in certain locations. 
The latter also speaks to the weaknesses related to the weak project description, consideration of alternatives and impact prediction, which seems to be the result of too early, and one-off engagement. The specialists continually highlighted as an explanation for these weaknesses that they are involved at a stage when not all information is available, and not in a manner that enables them to appropriately influence the design of projects. A generic and poorly defined project description, leads to difficulties in dealing meaningfully with alternatives and impact prediction. The solution put forward is to avoid having the BIA as a one-off input, and to rather have it as more of an iterative process, where the biodiversity assessment is reconsidered and updated as new information becomes available relating to for example the project design and/or alternatives.

The results therefore also suggest that EAPs do not provide proper support to biodiversity specialists. For example, EAPs may not give biodiversity specialists sufficient information; incorporate the findings and recommendations of the BIA accurately or adequately; provide adequate opportunity to specialists to review how their recommendations, gaps, uncertainties, etc. have been reflected in EIA documentation, to ensure findings are adequately reflected, and to address/ respond to stakeholder comments and input. Moreover, EAPs expect specialists to provide conclusive results and recommendations, even when they are not justified to do so; specialists are often not provided with adequate project descriptions by EAPs; alternatives are rarely provided by EAPs, are fatally flawed or not viable; alternatives are often not accepted by the client/EAP; the biodiversity specialist 'does not see or respond to' public comments on biodiversity issues and impacts raised in the BIA report; and there is a disconnect between the content of the BIA report and the concluding summary, particularly with regard to uncertainty and gaps in information.

While our results have used EIA practice from a biodiversity hotspot region in South Africa as a case study focus, the findings have implications for practice elsewhere. Our findings resonate with long term criticisms of the treatment of ecological and biodiversity factors in EIA. They point to problems with fragmentation and reductionism whereby individual elements of EIA and the individual experts responsible are isolated from consideration of the whole - i.e. failing to take an integrated approach. For progress to biodiversity conservation it is essential that best practice EIA principles, such as being integrated and participative, become embedded in the work of all practitioners in any given assessment.

\section{References}

Atkinson, S.F., Bhatia, S., Schoolmaster, F.A. \& Waller, W.T. 2000. Treatment of biodiversity impacts in a sample of US Environmental Impact Statements. Impact Assessment Project Appraisal, 18:271-82.

Barker, A. \& Jones, C.E. 2013. A critique of the performance of EIA within the offshore oil and gas sector. Environmental Impact Assessment Review, 43: 31-39.

Barker, N.P., Clark, V.R. \& Mucina, L. 2009. The Sneeuberg: A new centre of floristic endemism on the Great Escarpment, South Africa. Southern African Journal of Botany, 75(2):196-238. 
Barrow, C. 2006. Environmental management for sustainable development. 2nd Ed. New York, USA: Routledge.

Beanlands, G.E. \& Duinker, P.N. 1983. An ecological framework for Environmental Impact Assessment in Canada. Halifax, Canada: Institute for Resource and Environmental Studies, Dalhousie University.

Bond, A.J., Pope, J., Morrison-Saunders, A., Retief, F.P. \& Gunn, J. 2014. Impact assessment: Eroding benefits through streamlining? Environmental Impact Assessment Review, 45: 4653.

Briggs, S. Hudson, M.D. (2013) Determination of significance in ecological impact assessment: past change, current practice and future improvements, Environmental Impact Assessment Review, 38, 16-25

Brown, A. and G. McDonald (1995), 'From environmental impact assessment to environmental design and planning', Australian Journal of Environmental Management, 2 (2), $65-77$.

Brownlie, S. 2005. Guideline for involving biodiversity specialists in EIA processes, 1st Ed. Cape Town, South Africa: Provincial Government of the Western Cape: Department of Environmental Affairs and Development Planning.

Brownlie, S., Walmsley, B. \& Tarr, P. 2006. Situation assessment on the integration of biodiversity issues in Impact Assessment and decision making in Southern Africa. Capacity building in biodiversity in Impact Assessment: Southern African Institute for Environmental Assessment and deVilliers Brownlie Associates.

Brownlie, S., Walmsley, B. \& Tarr, P. 2006a. Guidance document on biodiversity, impact assessment and decision making in Southern Africa. The Southern African Institute for Environmental Assessment.

Brownlie, S., Walmsley, B. \& Tarr, P. 2006b. Situation assessment on the integration of biodiversity issues in Impact Assessment and decision making in Southern Africa. Capacity building in biodiversity in Impact Assessment: Southern African Institute for Environmental Assessment and deVilliers Brownlie Associates.

Butchart, S.H.M., Walpole, M., Collen, B., Van Strien, A., Scharlemann, J.P.W., Almond, R.E.A., Baillie, J.E.M., Bomhard, B., Brown, C. \& Bruno, J. 2010. Global biodiversity: Indicators of recent declines. Science, 328(5982):1164-8.

Byron, H.J., Treweek, J.R., Sheate, W.R. \& Thompson, S. 2000. Road developments in the UK: An analysis of ecological assessment in Environmental Impact Statements produced between 1993 and 1997. Journal of Environmental Planning and Management, 43(1):71-97.

Canelas, L., Almansa, P., Merchan, M. \& Cifuentes, P. 2005. Quality of Environmental Impact Statements in Portugal and Spain. Environmental Impact Assessment Review, 25(3):217-25. 
Cape, L., Retief, F., Lochner, P., Bond, A and Fischer, T. (2018) 'Exploring pluralism - different stakeholder views of the expected and realised value of Strategic Environmental Assessment (SEA)', Environmental Impact Assessment Review, vol 69, pp32-41

Cashmore, M., Christophilopoulos, E. \& Cobb, D. 2002. An evaluation of the quality of Environmental Impact Statements in Thessaloniki, Greece. Journal of Environmental Assessment Policy and Management, 4(4):371-95.

Cashmore, M (2004). The role of science in environmental impact assessment: Process and procedure versus purpose in the development of theory. Environmental Impact Assessment Review, 24(4), 403-426.

CBD. 2002. COP 6 Decision VI/7: Identification, monitoring, indicators and assessments. Hague, Netherlands: Conference of the Parties to the Convention on Biological Diversity. http://www.cbd.int/decisions/default.shtml.

CBD. 2006. COP 8 Decision VIII/28. Impact assessment: Voluntary guidelines on biodiversityinclusive impact assessment. Curitiba, Brazil: Conference of the Parties to the Convention on Biological Diversity. http://www.cbd.int/decisions/default.shtml.

Cilliers, D. and Retief, F. (2017) 'The extent and status of environmental management frameworks (EMFs) in South Africa, 2006 - 2015', South African Geographical Journal, vol 99(3), pp283-300

Cooney, R. 2004. The precautionary principle in biodiversity conservation and natural resource management: An issues paper for policy-makers, researchers and practitioners. Cambridge, England: World Conservation Union.

Cooper, L.M. \& Sheate, W.R. 2002. Cumulative effects assessment: A review of UK Environmental Impact Statements. Environmental Impact Assessment Review, 22(4):415439.

De Villiers, C., Brownlie, S. \& Manuel, J. 2008. 'Biodiversity mainstreaming' and EIA: Art, science or myth? International Association for Impact Assessment, Conference Proceedings. Perth, Australia.

De Villiers, C., Driver, A., Clark, B., Euston-Brown, D., Day, L., Job, N., Helme, N., Holmes, P., Brownlie, S. \& Rebelo, T. 2005. Ecosystem guidelines for Environmental Assessment in the Western Cape. Kirstenbosch, South Africa: Fynbos Forum and Botanical Society of South Africa.

De Villiers, C. E., \& Hill, R. C. (2008). Environmental management frameworks as an alternative to farm-level EIA in a global biodiversity hotspot: A proposal from the Cape Floristic Region, Journal of Environmental Assessment Policy and Management, 10, 333-360.

De Witt, M., Pope, J., Retief, F., Bond, A., Morrison-Saunders, A. and Steenkamp, C. 2019 Biodiversity offsets in EIA: Getting the timing right, Environmental Impact Assessment Review, vol 75, pp1-12 
Dickson, B. \& Cooney, R. 2005. Biodiversity and the precautionary principle: Risk and uncertainty in conservation and sustainable use. USA: Earthscan/James \& James.

Dietz, T. \& Stern, P.C. 2008. Public participation in Environmental Assessment and decision making. Washington, USA: National Academies Press.

Drayson, K., Wood, G., Thompson, S. (2015) Assessing the quality of the ecological component of English Environmental Statements, Journal of Environmental Management, $160,241-253$

Ehrlich, A., Ross, W., 2015. The significance spectrum and EIA significance determinations. Impact Assessment Project Appraisal 33 (2), 87-97.

ENVIS. 2005. Global Biodiversity Hotspots with special emphasis on Indian Hotspots.

European Commission. 2013. Guidance on integrating climate change and biodiversity into Environmental Impact Assessment. Europe.

Fairfax, S.K. (1978), 'A disaster in the environmental movement: the National Environmental Policy Act has wasted environmentalist's resources on processing papers', Science, 199, 743-8.

GDARD. 2012. Requirements for biodiversity assessments: Version 2. Johannesburg: Gauteng Department of Agriculture and Rural Development.

Geneletti, D. 2002. Ecological evaluation for Environmental Impact Assessment. Utrecht: The Netherlands: Netherlands Geographical Studies (NGS).

Gibson, R. (1993), 'Environmental assessment design: lessons from the Canadian experience', The Environmental Professional, 15, 12-24.

Glasson, J., Therivel, R. \& Chadwick, A. 2012. Introduction to Environmental Impact Assessment. 4th ed. New York, USA: Routledge.

Goutier, M., Balfors, B. \& Mörtberg, U. 2006. Biodiversity in Environmental Assessmentcurrent practice and tools for prediction. Environmental Impact Assessment, 26:268-86

Hallat, T.W., Retief, F.P. \& Sandham, L.A. 2015. The Quality of Biodiversity Inputs to EIA in Areas with High Biodiversity Value- Experience from the Cape Floristic Region, South Africa. Journal of Environmental Assessment Policy and Management, 17(3).

Hilborn, R. and C. Walters (1981), 'Pitfalls of environmental baseline and process studies', Environmental Impact Assessment Review, 2, 265-78.

Hollick, M. (1986), 'Environmental impact assessment: an international evaluation', Environmental Management, 10, 157-78. 
Holling, C. (ed.) (1978), Adaptive Environmental Assessment and Management, Chichester: John Wiley \& Sons.

Huggett, A.J. 2005. The concept and utility of 'ecological thresholds' in biodiversity conservation. Biological Conservation, 124(3):301-310.

IAIA and IEA - International Association for Impact Assessment and Institute for Environmental Assessment UK (1999), Principles of Environmental Impact Assessment Best Practice, available at www.iaia.org/uploads/pdf/principlesEA_1.pdf (accessed 22 June 2017).

IAIA. 2005. Biodiversity in Impact Assessment. Special Publication Series. Fargo, USA: International Association for Impact Assessment.

IEMA (2011), "Special Report - the state of environmental impact assessment in the UK", available at <https://www.iema.net/system/files/iema20special20report20web.pdf>, last accessed 17 January 2013.

Keatimilwe, K. \& Ashton, P.J. 2005. Guideline for the review of specialist input in EIA processes. Department of Environmental Affairs and Development Planning, Cape Town: CSIR.

Kennedy A, Ross W. 1992. An approach to integrate impact scoping with environmental impact assessment. Environmental Management. 16(4):475-484.

King, N.A., Maree, G. \& Muir, A. 2009. Freshwater systems. In: Strydom, H., King, N., eds. Environmental management in South Africa. 2nd ed. Cape Town, South Africa: Juta Law, p. 425-54.

Kidd, M., Retief, F. \& Alberts, R. (2018) Integrated Environmental Assessment and Management. In: King, N., Strydom, H. \& Retrief, F., eds. Environmental Management in South Africa. Cape Town: Juta Press, p 1213-77.

Kolhoff, A., Schiff, B., Verheem, R. \& Slootweg, R. 2009. Environmental Assessment. In: Slootweg, R., Rajvanshi, A., Mathur, V. \& Kolhof, A., eds. Biodiversity in Environmental Assessment: Enhancing ecosystem services for human well-being. Cambridge, New York: Cambridge University Press, p. 125-53.

Lee, N., Colley, R., Bonde, J. \& Simpson, J. 1999. Reviewing the quality of environmental statements and environmental appraisals. Manchester: EIA Centre, Department of Planning and Landscape, University of Manchester.

Mandelik, Y., Dayan, T. \& Feitelson, E. 2005. Planning for biodiversity: the role of Ecological Impact Assessment. Conservation Biology, 19(4):1254-61

Marais, M., Retief, F.P., Sandham, L.A. \& Cilliers, D.P. 2015. Environmental management frameworks: Results and inferences of report quality performing in South Africa. South African Geographical Journal, 97(1), 83-99. 
McGrath, C. \& Bond, A. 1997. The quality of Environmental Impact Statements: A review of those submitted in Cork, Eire from 1988-1993. Impact Assessment and Project Appraisal, 12(1):43-52.

Miller, G.T. \& Spoolman, S. 2011. Living in the environment: Principles, connections and solutions. 17th ed. Canada: Brooks/Cole, Cengage learning.

Morgan, R.K. 2012. Environmental impact assessment: The state of the art. Impact Assessment and Project Appraisal, 3:5-14.

Morrison-Saunders, A. 1996. Environmental Impact Assessment as a Tool for Ongoing Environmental Management. Project Appraisal, 11(2), 95-104.

Morrison-Saunders A (2018) Advanced Introduction to Environmental Impact Assessment, Cheltenham: Edward Elgar.

Morrison-Saunders, A. \& Retief, F. 2012. 'Walking the Sustainable Development Talk Progressing the Practice of Environmental Impact Assessment (EIA)', Environmental Impact Assessment Review, volume 36: 34-41.

Morrison- Saunders, A., Pope, J., Gunn, J., Bond, A.J. \& Retief, F.P. 2014. Strengthening impact assessment: A call for integration and focus. Impact Assessment and Project Appraisal, 32(1): 2-8.

Münster, F. 2005. Guidelines for determining the scope of specialist involvement in EIA processes. 1st ed. Provincial Government of the Western Cape, Department of Environmental Affairs and Development Planning, Cape Town: CSIR.

Myers, N., Mittermeier, R., Mittermeier, C., Da Fonseca, G. \& Kent, J. 2000. Biodiversity hotspots for conservation priorities. Nature, 403(6772):853-8.

Noble, B. (2015), Introduction to Environmental Impact Assessment: A Guide to Principles and Practice, third edition, Don Mills, Ontario: Oxford University Press.

Olivier, N.J.J., Myakayaka, A.G.M. \& Richards, R.L. 2009. Indigenous plants. In: Strydom, H. \& King, N., eds. Environmental management in South Africa. 2nd ed. Cape Town, South Africa: Juta Law, p. 342-93.

Peh, K.S.H., Balmford, A., Bradbury, R.B., Brown, C., Butchart, S.H.M., Hughes, F.M.R., Stattersfield, A., Thomas, D.H.L., Walpole, M., Bayliss, J., Gowing, D., Jones, J.P.J., Lewis, S.L., Mulligan, M., Pandeya, B., Stratford, C., Thompson, J.R., Turner, K. * Birch, J.C. 2013. TESSA: a toolkit for rapid assessment of ecosystem services at sites of biodiversity conservation importance. Ecosystem services, 5:51-57.

Peterson, K. 2010. Quality of Environmental Impact Statements and variability of scrutiny by reviewers. Environmental Impact Assessment, 30(3):169-76.

Pope, J., Bond, A., Morrison-Saunders, A. \& Retief, F.P. 2013. Advancing the theory and practice of Impact Assessment: Setting the research agenda. Environmental Impact Assessment, 41:1-9. 
Rajvanshi, A., Mathur, V.B. \& Slootweg, R. 2009. Biodiversity in Environmental Impact Assessment. In: Slootweg, R., Rajvanshi, A., Mathur, V. \& Kolhof, A., eds. Biodiversity in Environmental Assessment: Enhancing ecosystem services for human well-being. Cambridge, New York: Cambridge University Press, p. 154-204.

Retief, F., Jones, C. \& Jay, S. 2007. The status and extent of Strategic Environmental Assessment (SEA) practice in South Africa- 1996-2003. South African Geographic Journal, 89(1):44-54.

Retief, F. \& Chabalala, B. 2009. The cost of environmental impact assessment (EIA) in South Africa. Journal of Environmental Assessment Policy and Management, 11: 51-68.

Retief, F. 2010. The evolution of environmental assessment databases- Critical perspectives from South Africa. Journal of Environmental Assessment Policy and Management, 12(4): 123.

Retief, F. Morrison-Saunders, A., Geneletti, D. and Pope, J. 2013 Exploring the psychology of trade-off decision making in ElA', Impact Assessment and Project Appraisal, vol 31(1), pp 1323

Retief, F., Bond, A., Pope, J., Morrison-Saunders, A. and King, N. 2016 Global megatrends and their implications for Environmental Assessment (EA) practice, Environmental Impact Assessment Review, vol 61, pp52-60

Rouget, M., Richardson, D., Cowling, R., Lloyd, J. \& Lombard, A. 2003. Current patterns of habitat transformation and future threats to biodiversity in terrestrial ecosystems of the Cape Floristic Region, South Africa. Biological Conservation, 112:63-85.

Rumsey, A.B. 2009. Terrestrial wild animals. In: Strydom, H. \& King, N., eds. Environmental management in South Africa. 2nd ed. Cape Town, South Africa: Juta Law, p. 394-424.

Sallenave, J. 1994. Giving traditional ecological knowledge its rightful place in Environmental Impact Assessment. North Perspective, 22(1):16-8.

Sandham, L.A., Carol, T.H. \& Retief, F.P. 2010. The contribution of environmental impact assessment (EIA) to decision making for biological pest control in South Africa- The Case of Lantana Camara. Biological Control, 55(2): 141-149.

Sandham, L.A., Hoffman, A.R. \& Retief, F.P. 2008a. Reflections on the quality of mining EIA reports in South Africa. Journal of South African Institute for Mining Metal, 108(11):701-6.

Sandham, L.A., Moloto, M.J. \& Retief, F.P. 2008b. The quality of environmental impact reports for projects with the potential of affecting wetlands in South Africa. Environmental Impact Assessment, 28:229-40.

Sandham, L.A., Van Heerden, A.J., Jones, C.E., Retief, F.P. \& Morrison-Saunders, A.N. 2013. Does enhanced regulation improve EIA report quality? Lessons from South Africa.

Environmental Impact Assessment, 38:155-62. 
Sippe, R. (1997), 'Establishing rules for environmental acceptability for reviewing EAs: the Western Australian experience', Environmental Assessment, 5 (1), 17-20.

Sippe, R. (1999), 'Criteria and standards for assessing significant impact', in J. Petts (ed.), Handbook of Environmental Impact Assessment Volume 1: Environmental Impact Assessment: Process, Methods and Potential, Oxford: Blackwell Science, pp. 74-92.

Slootweg, R. 2005. Biodiversity assessment framework: Making biodiversity part of corporate social responsibility. Journal of Impact Assessment and Project Appraisal, 23:3746.

Slootweg, R. 2009. Interpretation of biodiversity. In: Slootweg R, Rajvanshi A, Mathur V, Kolhof $A$, editors. Biodiversity in Environmental Assessment: Enhancing ecosystem services for human well-being. New York, USA: Cambridge University Press, p. 14-58.

Slootweg, R., Kolhoff, A., Verheem, R. \& Höft, R. 2006. Biodiversity in EIA and SEA. Background document to CBD decision VIII/28, voluntary guidelines on biodiversity inclusive impact assessment. Netherlands: International Association for Impact Assessment (IAIA).

Söderman, T. 2005. Treatment of biodiversity issues in Finnish Environmental Impact Assessment. Impact Assessment and Project Appraisal, 23(2):87-99.

Söderman, T. 2006. Treatment of biodiversity issues in Impact Assessment of electricity power transmission lines: A Finnish case review. Environmental Impact Assessment, 26(4):319-38.

Sowman, M., Fuggle, R. and Preston, G. (1995) 'A review of the evolution of environmental evaluation procedures in South Africa', Environmental Impact Assessment Review, vol 15, pp45-67

Steffen, W., Richardson, K., Rockström, J., Cornell, S.E., Fetzer, I., Bennett, E.M., Biggs, R., Carpenter, S.R., De Vries, W., De Wit, C.A., Folke, C., Gerten, D., Heinke, J., Mace, G.M., Persson, L.M., Ramanathan, V., Reyers, B., Sörlin, S., 2015. Planetary boundaries: guiding human development on a changing planet. Science 347 (6223), 736-753.

Steinemann, A. (2001), 'Improving alternatives for environmental impact assessment', Environmental Impact Assessment Review, 21 (1), 3-21.

Stevenson, M.G. 1996. Indigenous knowledge in Environmental Assessment. Arctic, 49(3):278-91

Thompson, S., Treweek, J.R., Thurling, D.J. 1997. The ecological component of Environmental Impact Assessment: A critical review of British environmental statements. Journal of Environmental Planning and Management, 40(2):157-72.

Treweek, J. 1996. Ecology and Environmental Impact Assessment. Journal of Applied Ecology, 33(2):191-9.

Treweek, J. 1999. Ecological Impact Assessment. Malden, USA: Blackwell Science. 
Treweek, J.R., Thompson, S., Veitch, N. \& Japp, C. 1993. Ecological assessment of proposed road developments: A review of environmental statements. Journal of Environmental Planning and Management, 36(3):295-307.

UNESCO. 2004. Convention concerning the protection of the world cultural and natural heritage: Decisions adopted at the 28th session of the World Heritage Committee. Suzhou: United Nations Educational, Scientific and Cultural Organization World Heritage Centre.

Warnken, J. \& Buckley, R. 1998. Scientific quality of tourism Environmental Impact Assessment. Journal of Applied Ecology, 35(1):1-8.

Wegner, A., Moore, S.A. \& Bailey, J. 2005. Consideration of biodiversity in Environmental Impact Assessment in Western Australia: Practitioner perceptions. Environmental Impact Assessment, 25:143-62.

Weiner, K. (1997), 'Basic purposes and policies of the NEPA regulations', in R. Clark and L. Canter (eds), Environmental Policy and NEPA: Past, Present and Future, Boca Raton: St Lucie Press, pp. 61-83.

Wessels, J., Retief, F. \& Morrison-Saunders, A. (2015) 'Appraising the value of independent EIA follow-up verifiers', Environmental Impact Assessment Review, vol 50, pp178-189

Wood, G. (2008), 'Thresholds and criteria for evaluating and communicating impact significance in environmental statements: "See no evil, hear no evil, speak no evil?"', Environmental Impact Assessment Review, 28, 22-38.

Yin, R (2003). Case Study Research: Design and Methods, 3rd Ed., Applied Social Research Methods Series, Vol. 5. London, UK: Sage Publications. 